\title{
Optical and magnetic properties of Yb ion-doped cobalt-based ZnO nanoparticles for DMS applications
}

\author{
T THANGEESWARI ${ }^{1,3}$, M PRIYA $^{2, *}$, J VELMURUGAN $^{3}$ and N PADMANATHAN ${ }^{4}$ \\ ${ }^{1}$ Department of Physics, Vel Tech MultiTech Engineering College, Chennai 600 062, India \\ ${ }^{2}$ Department of Physics, Saveetha Engineering College, Chennai 602 105, India \\ ${ }^{3}$ Department of Medical Physics, Anna University, Chennai 600 025, India \\ ${ }^{4}$ Department of Physics, Anna University, Chennai 600 025, India
}

MS received 8 April 2015; accepted 4 June 2015

\begin{abstract}
Well-crystalline structured $\mathrm{ZnO}$ nanoparticles with cobalt (Co) and ytterbium (Yb) multiple ions doping were successfully synthesized by the chemical precipitation technique. The structures, optical and magnetic properties of the samples were analysed with X-ray diffraction (XRD), UV-visible spectroscopy and magnetic measurements, respectively. In the XRD pattern of the pure $\mathrm{ZnO}$ and Yb co-doped samples, the formation of highly crystalline phase of pure $\mathrm{ZnO}$ was observed even at high Yb concentration. UV-vis spectra show a strong UV absorbance for all the samples with different absorbance maxima. Magnetic characterizations have shown that the sample with $1 \% \mathrm{Yb}$ co-doped $\mathrm{ZnO}$ : Co nanoparticles exhibited a clear ferromagnetic (FM) behaviour at room temperature. The $\mathrm{X}$-ray photoelectron spectral peaks for $\mathrm{Yb} 4 \mathrm{f}$ ions reveal $\mathrm{Yb}$ occupation of both $\mathrm{Yb}^{3+}$ as well as $\mathrm{Yb}^{2+}$ states. Hence, it can be confirmed that a clear FM behaviour at room temperature was exhibited by an imbalanced valence state of $Y b$ that strongly interacted with the $\mathrm{Co}^{2+}$. When compared to the Co-doped $\mathrm{ZnO}$, Yb co-doped $\mathrm{ZnO}$ exhibits a clear ferromagnetism at room temperature with high coercivity due to the contribution of both $3 \mathrm{~d}$ and $4 \mathrm{f}$ exchange interaction with the host matrix.
\end{abstract}

Keywords. Chemical synthesis; rare earth metals; co-doping; ferromagnetism.

\section{Introduction}

Dilute magnetic semiconductors (DMSs) have been one of the most interesting materials due to their potential application towards the spintronics, where the charge and spin of electrons is used simultaneously for the data processing in spin-based information storage and optical devices. ${ }^{1}$ The main challenge of the DMS's applications is to attain a ferromagnetic (FM) property at room temperature (RT). ${ }^{2}$ The $\mathrm{ZnO}$-based semiconductors have been demonstrated as an ideal DMS material due to high solubility of transition metals (TMs), good semiconducting properties, wide bandgap $(3.27 \mathrm{eV})$ and large exciton binding energy ( $60 \mathrm{meV})$ compared to the various materials such as Mn-doped GaAs and Mn-doped GaN. ${ }^{3} \mathrm{ZnO}$ doped with many TMs by DMSs was investigated, $\mathrm{Mn},{ }^{4,5} \mathrm{Co},{ }^{6-9} \mathrm{Ni}^{2,10} \mathrm{Fe}^{11-13}$ and $\mathrm{Cu},{ }^{2,14}$ and reported to have the high Curie temperature that is above RT. The local magnetic moment in doped TM ions leads to $\mathrm{sp}-\mathrm{d}$ exchange interaction that induces ferromagnetism at high temperature. However, it remains under debate whether the room temperature ferromagnetism (RTFM)

\footnotetext{
*Author for correspondence (priyam7373@gmail.com)
}

in TM-doped $\mathrm{ZnO}$ semiconductors is due to the intrinsic or extrinsic origin. ${ }^{15}$ On the other hand, some reports suggested that RTFM in $\mathrm{ZnO}$ is a intrinsic FM origin which may be due to oxygen deficiency, cation vacancy and defects in the crystal structure. ${ }^{15-17}$ Banerjee et $a l^{18}$ reported that the enhancement of ferromagnetism in pure $\mathrm{ZnO}$ powder upon thermal annealing was linked to the formation of oxygen vacancy $\left(\mathrm{V}_{\mathrm{O}}\right)$. Xu et $a l^{19}$ also reported ferromagnetism in $\mathrm{ZnO}$ thin films and attributed it to the intrinsic defects. Till date, the researchers have controversial issue with this observed ferromagnetism in DMS, which is due to magnetic impurities or intrinsic nature of the material. ${ }^{2}$ To overcome this, the various research groups are finding the versatile DMS material for spintronics and other magneto-optical device fabrication.

In case of Co-doped $\mathrm{ZnO}$-based DMS, till date there is no clear concept about the nature and origin of magnetic properties. Some reports suggested that the presence of the double exchange interaction in Co clusters is the reason for the origin of ferromagnetism in $\mathrm{Zn}_{1-x} \mathrm{Co}_{x} \mathrm{O} .^{7}$ In contrast, in recent times the absence of ferromagnetism in Co-doped $\mathrm{ZnO}$ nanoparticles were reported by Duan et $a l^{20}$ and Rao-Deepak. ${ }^{21}$ Hence the exact origin of ferromagnetism in magnetic $\mathrm{Co}^{2+}$ ion-doped $\mathrm{ZnO}$-based 
DMSs is controversial and still in serious discussion. However, it is believed that the presence of additional carrier introduced by co-doping can enhance the ferromagnetism in $\mathrm{ZnO}: \mathrm{Co}^{2+}$. In past decades, the effect of co-doping on RTFM in GaN doped with the rare earth (RE) element $\mathrm{Gd}$ was reported. Hite et $a l^{22}$ reported the effect of $\mathrm{Si}$ co-doping on the electrical and magnetic properties of $\mathrm{GaN}: \mathrm{Gd}$ and found four times increase in saturation magnetization $\left(M_{\mathrm{s}}\right)$. Zhou et $a l^{23}$ reported an approximately seven times enhancement in $\mathrm{GaN}: \mathrm{Gd}$ magnetization by Si co-doping. Only few reports have been published with additional carrier-doped $\mathrm{ZnO}$-based DMSs. Also aggregation in $\mathrm{ZnO}$ : Co lattice affects the magnetic interaction in $\mathrm{ZnO} \mathrm{DMS}$. The effect due to aggregation can be controlled by the co-doping and growth technique. ${ }^{24}$

In recent times, the RE-doped $\mathrm{ZnO}$ semiconductors are an active research area. In RE metal-doped oxide semiconductors, the $4 \mathrm{f}$ electrons in RE ion are localized and directed the exchange interactions via $5 \mathrm{~d}$ or 6 s conduction electrons, which offer high total magnetic moments per atom because of their high orbital momentum. ${ }^{25,26}$ Therefore, unlike the $\mathrm{d}$ states, f electrons can couple strongly with the host s electrons, leading to the possibility of electron-mediated ferromagnetism in these materials. ${ }^{27,28}$ Earlier results show that RE doping process in the semiconductor host material plays an important role to obtain interesting optical and magnetic properties because of its efficient energy transfer property that is used in magneto-optical device. ${ }^{29}$ On the other hand, the $4 \mathrm{f}$ RE dopants like $\mathrm{Eu}, \mathrm{Pr}$ and $\mathrm{Gd}$ have been widely investigated due to their high magnetic moments, excellent fluorescence properties and high stability. Therefore, it can be considered as an alternative to $3 \mathrm{~d}$ TMs to induce the RTFM. $^{24}$

Moreover, RE ions have special electronic structure which may be favourable for desired luminescent features; especially, their valence electrons located in $4 \mathrm{f}$ orbit surrounded by filled $5 \mathrm{~s}$ and $5 \mathrm{p}$ orbits. Due to the effective shielding by both $5 \mathrm{~s}$ and $5 \mathrm{p}$ orbits, the environment impact on $4 \mathrm{f}$ electron's transition is limited. ${ }^{3}$ Therefore the exact ferromagnetism without the inclusion of other interactions is measured. Consequently, the RE metal ions have very stable optical transition, many energy levels, many metastable states and a very good fluorescence in the UV and visible region, which is needed for desired luminescent features. Based on previous reports, obtaining good optical and magnetic properties from the nanomaterials is fully based on the doping of selective elements only. Among various $\mathrm{RE}$ ions, $\mathrm{Yb}$ is one of the interesting elements which exhibit unique optical features with their partially filled $\mathrm{f}$ electron states. In the electronic configuration of $\mathrm{Yb}^{3+}$, the $4 \mathrm{f}$ electron is less shielded than other RE ions which makes a high interaction with host lattice and shows the excellent sensitizer for TM ions. Also recent reports are confirmed that
$\mathrm{Yb}^{3+}$-doped laser material is a promising diode pumped laser medium. ${ }^{30}$

In this present study, for the first time the RTFM in chemically precipitated $\mathrm{Co}$ with $\mathrm{Yb}$ co-doped $\mathrm{ZnO}$ nanoparticles is discussed. In addition, their structural, optical and morphological features are also investigated. The aim of this study is the enhancement of luminescence properties and magnetic properties of the $\mathrm{ZnO}$ nanoparticles by co-doping with dual impurities (i.e., one is nonmagnetic $(\mathrm{Yb})$ and the other is magnetic material (Co)). The main challenge for this kind of materials is to attain their magnetic character at RT and good optical property in order to be useful for magneto-optical device applications.

\section{Experimental}

\subsection{Synthesis process}

The analytical grade, zinc nitrate tetrahydrate, cobalt nitrate tetrahydrate and ytterbium nitrate hexahydrate were used as starting materials. The materials were obtained from Merck (Germany 99.9\%), and used without further purification. The typical synthesis process is as follows: the stoichiometric amount of the above-mentioned starting materials were dissolved in $20 \mathrm{ml}$ of deionized (DI) water separately under stirring. The $\mathrm{Yb}$ concentrations are fixed as 1,3 and $5 \%$ with the $10 \%$ constant cobalt concentration. The precursor solutions were rapidly mixed together to form a homogeneous mixture. After that, $1 \mathrm{M}$ of $\mathrm{NaOH}$ solution was added dropwise to the above mixture over $20 \mathrm{~min}$ at RT. Immediately, $\mathrm{Zn}(\mathrm{OH})_{2}$ was formed as white precipitate. The stirring was continued for $2 \mathrm{~h}$ and aged for $12 \mathrm{~h}$ to complete the nucleation process. Finally, the precipitate was washed with DI water, ethanol, and acetone consecutively through centrifugation to remove the possible ions remaining in the final product. The end product was dried and calcined at $300^{\circ} \mathrm{C}$ for $3 \mathrm{~h}$. For comparison, pure $\mathrm{ZnO}$ nanoparticle was also synthesized by following the same procedure without the addition of $\mathrm{Co}$ and $\mathrm{Yb}$ ions. For easy identification, the prepared samples were named as $\mathrm{Z}$ (pure $\mathrm{ZnO}$ ), ZC (cobalt-doped $\mathrm{ZnO}), \mathrm{ZCY} 1$ (1\% Yb doped with cobalt and $\mathrm{ZnO}), \mathrm{ZCY} 3$ (3\% Yb doped with cobalt and $\mathrm{ZnO}$ ) and $\mathrm{ZCY} 5$ (5\% Yb doped with cobalt and $\mathrm{ZnO}$ ).

\subsection{Characterization}

The crystalline structure was evaluated by X-ray diffraction (XRD) using PAN analytical instrument, using CuK $\alpha$ radiation $(\lambda=1.5406 \AA)$ with the scanning rate of $0.05^{\circ} \mathrm{s}^{-1}$ in the $2 \theta$ range from $20^{\circ}$ to $80^{\circ}$. Fourier transform infrared (FTIR) spectra were observed with Perkin Elmer infrared spectrophotometer. Morphology and microstructure were identified by high-resolution scanning electron microscope (HRSEM, Quanta 200 FEG 
$\sim 5 \mathrm{kV}$ ) equipped with energy-dispersive X-ray (EDX) analysis and transmission electron microscope (TEM Philips Model: CM-20), respectively. UV-vis spectra of the nanoparticles were obtained using (Shimadzu UV-2450) UV-vis-NIR spectrophotometer. Photoluminescence (PL) spectra were recorded using a $\mathrm{He}-\mathrm{Cd}$ laser source with an excitation wavelength of $325 \mathrm{~nm}$ by Perkin Elmer L45 fluorescence spectrophotometer at RT. X-ray photoelectron spectra (XPS) were recorded using an AlK $\alpha$ $(h v=1486.6 \mathrm{eV})$ used as X-ray source by sigma probe (Thermo Scientific). Magnetic studies of the prepared samples were carried out on vibrating sample magnetometer (Lakeshore VSM 7410) at RT.

\section{Results and discussion}

\subsection{Structural study}

XRD pattern of pure and $\mathrm{Co}$ with $\mathrm{Yb}$ co-doped $\mathrm{ZnO}$ nanoparticles is shown in figure 1 . It is evident that diffraction peaks of all the samples can be indexed to the hexagonal wurtzite structure of $\mathrm{ZnO}$. Only the diffraction lines of the wurtzite $\mathrm{ZnO}$ were observed without any other peaks in Co-doped $\mathrm{ZnO}$ and $\mathrm{Yb}$ co-doped (even up to $5 \%$ of $\mathrm{Yb}$ ) nanoparticles. ${ }^{31}$ It clearly indicates that the $\mathrm{Co}$ and the $\mathrm{Yb}$ ions are successfully incorporated into the $\mathrm{ZnO}$ lattice site. Compared to pure $\mathrm{ZnO}$, the doped samples show the low intensity and increased full-width halfmaxima in XRD patterns. In detail, the peak (101) of Codoped $\mathrm{ZnO}$ nanoparticles shows a slight shift towards higher angle $\sim 0.11^{\circ}$ which has good agreement with previous report. ${ }^{32}$ Whereas the $\mathrm{Yb}$ co-doped sample shows that the peak (101) shift towards the lower angle due to the additional strain induced by the co-dopant in $\mathrm{ZnO}$

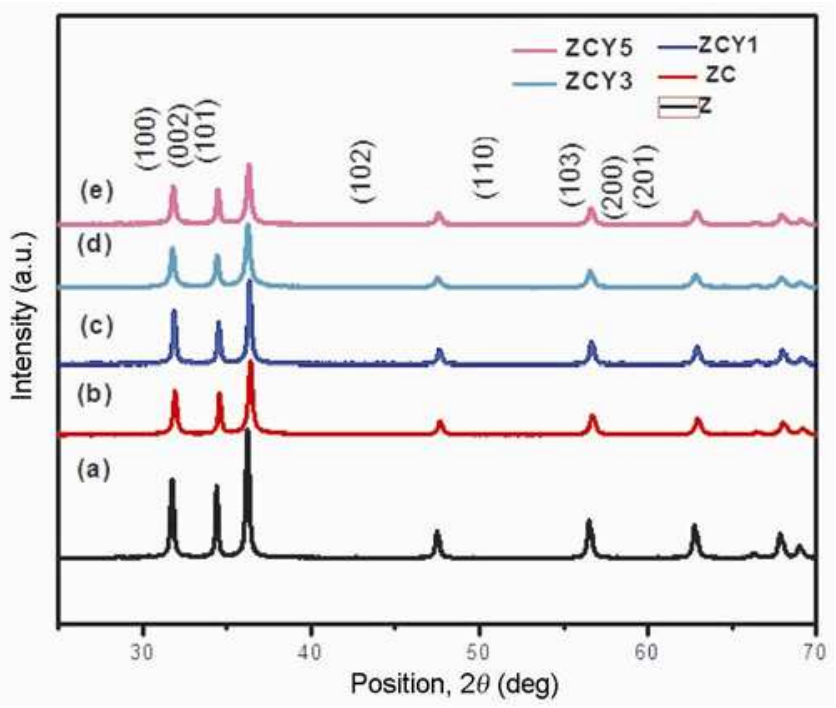

Figure 1. XRD patterns of pure and $\mathrm{Co}$ with $\mathrm{Yb}$ co-doped $\mathrm{ZnO}$ nanoparticles. lattices. ${ }^{29,33}$ The shift towards the lower angle illustrates that $\mathrm{Yb}^{3+}$ ions with larger ionic radius $(1.01 \AA)$ have been successfully incorporated into the $\mathrm{ZnO}$ lattice and substituted the $\mathrm{Zn}^{2+}$ ionic sites $(0.74 \AA) .{ }^{34}$ The average particle size of pure and Co-doped $\mathrm{ZnO}$ nanoparticles are calculated with the maximum intensity peak (101) by using the Scherrer equation. It is found to be in the range of 25-19 nm for $\mathrm{ZnO}$ : Co with $\mathrm{Yb}$ doping nanoparticles.

\subsection{Morphological studies}

Figure $2 \mathrm{a}-\mathrm{f}$ represents the SEM images of pure ( $\mathrm{a}$ and $\mathrm{b}$ ), Co-doped $\mathrm{ZnO}$ (c and $\mathrm{d}$ ) and $1 \% \mathrm{Yb}$ co-doped $\mathrm{ZnO}$ (e and f) nanoparticles. Figure $2 \mathrm{a}$ and $\mathrm{b}$ shows the undefined aggregated morphology of the pure $\mathrm{ZnO}$ nanoparticles. By adding $\mathrm{Co}$ into $\mathrm{ZnO}$ the morphology has been converted to flake-like structure (figure $2 \mathrm{c}$ and $\mathrm{d}$ ). There is no significant change observed in the surface morphology with the addition of $\mathrm{Yb}$. Captured SEM images of the $\mathrm{Yb}$ co-doped $\mathrm{ZnO}$ nanoparticles clearly show that the self-assembled nanoflakes appeared with coarse morphology. With the addition of $\mathrm{Yb}$ into $\mathrm{ZnO}$, the typical nanoflakes are self-assembled together and try to form the flower-like morphology as can be seen in figure $2 \mathrm{e}$ and $\mathrm{f}$. This result indicates that the addition of $\mathrm{Yb}$ varies the surface energy and connects the nanoflakes together forming the flower-like microstructure for $1 \%$ $\mathrm{Yb}$ co-doped $\mathrm{ZnO}$. The significant variation in the grain size was observed by the addition of $\mathrm{Yb}$, which may be due to the interaction of $\mathrm{Yb}$ and $\mathrm{Zn}$ lattice. The EDX spectra for $\mathrm{Co}$ with $1 \% \mathrm{Yb}$ co-doped $\mathrm{ZnO}$ nanoparticles are shown in figure $3 a-c$. The peak intensities in the spectra are consistent with appropriate concentrations of atoms present and assured the existence of $\mathrm{Zn}, \mathrm{Co}, \mathrm{Yb}$ and $\mathrm{O}$ without any impurities. To further confirmation, TEM analysis was taken for $1 \mathrm{~mol} \%$ of $\mathrm{Yb}$-doped $\mathrm{ZnO}$ nanoparticles which are shown in figure $4 \mathrm{a}-\mathrm{d}$. TEM images indicate the formation of nanoflake microstructure of the compound with coarse morphology. The observed TEM photographs confirm that coarse frame of nanoparticles assembled together and formed nanoflakes.

\subsection{Optical studies}

The UV-vis absorption spectra were used to find possible changes in electronic structure. ${ }^{18}$ The UV-vis absorption spectra of pure and $\mathrm{Co}$ with $\mathrm{Yb}$ co-doped $\mathrm{ZnO}$ nanoparticle are shown in figure 5a. The spectrum of pure $\mathrm{ZnO}$ has strong UV emission peak at $358 \mathrm{~nm}$. The UV emissions are commonly due to the reason of direct recombination of free excitons of $\mathrm{ZnO} .^{29}$ After being doped with $\mathrm{Co}$ and $\mathrm{Yb}$, the absorption peaks shifted towards higher wavelength region from 358 to $363 \mathrm{~nm}$, i.e., red shifted with the increase in the $\mathrm{Yb}$ concentrations. ${ }^{35}$ The $\mathrm{Yb}^{3+}$ ions introduce the electronic state impurity energy band 

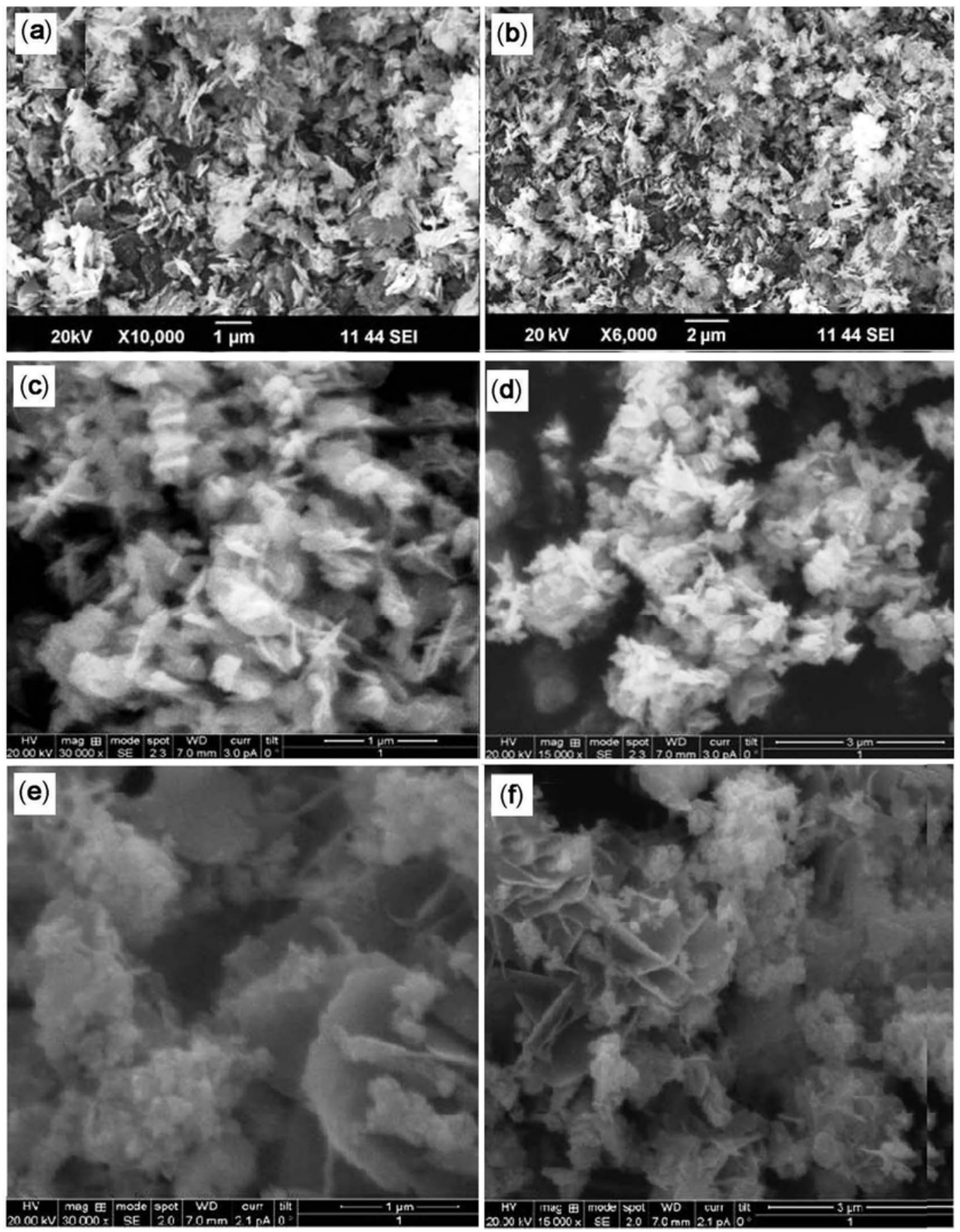

Figure 2. Scanning electron micrographs of (a and b) pure $\mathrm{ZnO}$, (c and $\mathbf{d}) \mathrm{Co}$-doped $\mathrm{ZnO}$ and (e and $\mathbf{f}$ ) $1 \% \mathrm{Yb}$ co-doped $\mathrm{ZnO}$ : Co nanoparticles.

Table 1. Atomic concentration of elements for pure and $\mathrm{Co}: \mathrm{Yb}$ co-doped $\mathrm{ZnO}$ nanocrystals measured from the EDS analysis.

\begin{tabular}{lcccc}
\hline Compound name & Atomic \% of $\mathrm{Zn}$ & Atomic \% of Co & Atomic \% of $\mathrm{Yb}$ & Atomic \% of O \\
\hline $\mathrm{Z}$ & 59.73 & - & - & 39.74 \\
$\mathrm{ZC}$ & 50.15 & 9.81 & - & 40.04 \\
$\mathrm{ZCY} 1$ & 49.23 & 9.41 & 0.97 & 40.37 \\
\hline
\end{tabular}



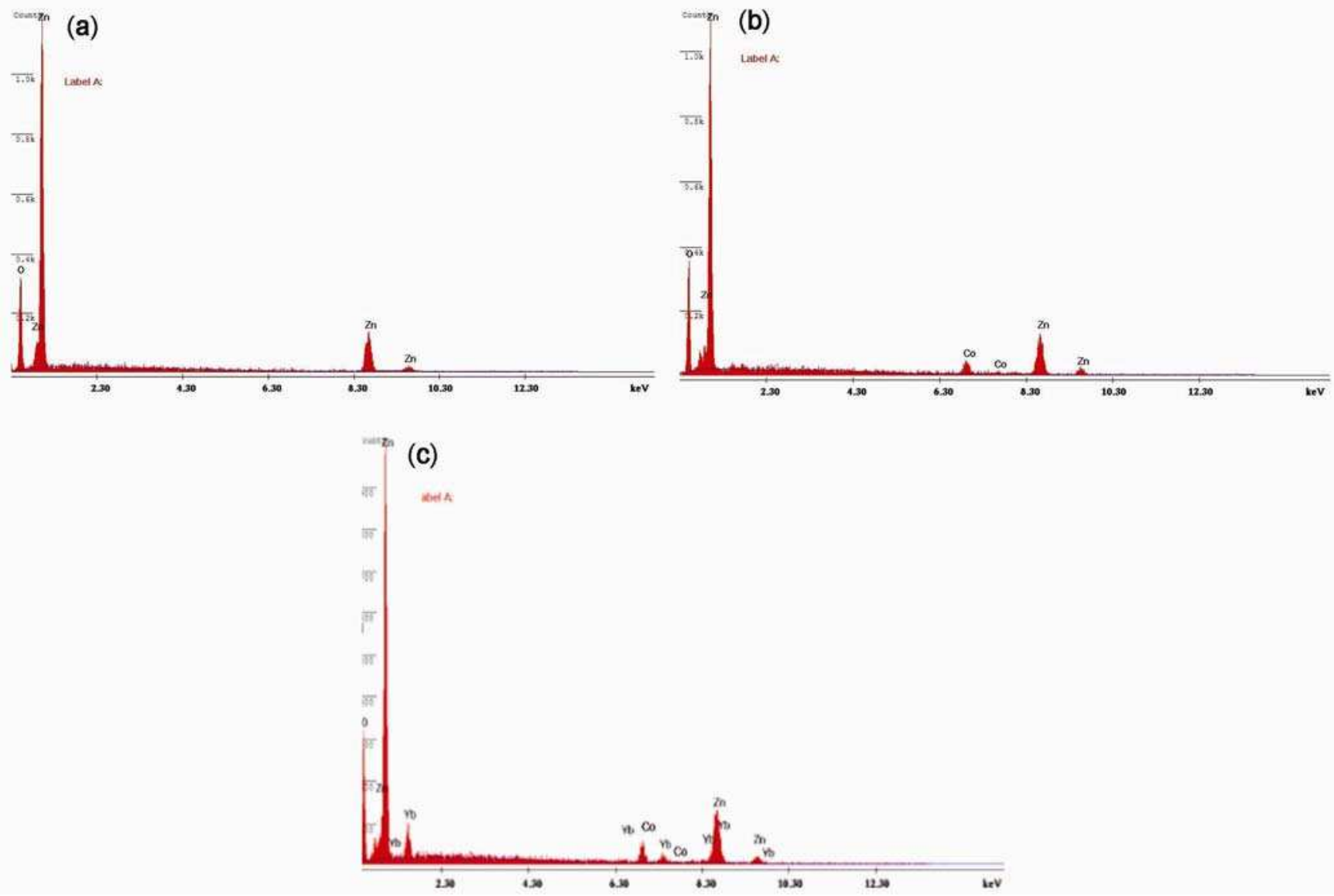

Figure 3. (a-c) Energy-dispersive X-ray spectra of pure and Co with $\mathrm{Yb}$ co-doped $\mathrm{ZnO}$ nanoparticles.

into the energy band of $\mathrm{ZnO}$ which are very close to the conduction band. This introduction of impurity band gives rise to the reduction in bandgap and red shift in UV region. ${ }^{35}$ Bandgap was measured with Tauc's plot by using the Mott and Davis relation $\alpha h v \sim\left(h v-E_{\mathrm{g}}\right)^{1 / 2}$ for allowed direct transitions as reported earlier. From figure $5 \mathrm{~b}$, energy bandgap $E_{\mathrm{g}}$ for $\mathrm{Co}$ with $\mathrm{Yb}$ co-doped $\mathrm{ZnO}$ nanoparticles is found to be in the range of $3.25-3.15 \mathrm{eV}$. Bandgap value for co-doped $\mathrm{Yb}^{3+}$ decreases when compared to pure and Co-doped samples. As a result, the electronic structure of $\mathrm{ZnO}$ nanoparticles can be tuned when $\mathrm{Yb}^{3+}$ ion is doped into $\mathrm{ZnO}$ lattice which may give the good optical properties for the doped samples. ${ }^{36}$

\subsection{PL studies}

$\mathrm{PL}$ spectra of the $\mathrm{Yb}$ co-doped $\mathrm{ZnO}$ : Co nanoparticles are shown in figure $6 \mathrm{a}$ and $\mathrm{b}$. A strong UV-visible emission band for the corresponding UV excitation of $325 \mathrm{~nm}$ is observed. The pure $\mathrm{ZnO}$ shows the characteristic emission band at $382.6 \mathrm{~nm}$ followed by the deep-level visible emission and it can be observed for all the samples. The UV emission arises from the recombination of exciton-exciton through collision process. ${ }^{29}$ Besides, a strong and broad green emission band at around $550 \mathrm{~nm}$ was observed in pure $\mathrm{ZnO}$. This deep-level visible band is commonly due to the intrinsic defects like oxygen vacancy and zinc interstitials. ${ }^{37}$ After the addition of Co (10\%), both the characteristic and deep-level emission intensity decreases due to the low intrinsic optical behaviour of the Co ions. This confirms the partial substitution of Co into $\mathrm{Zn}$ site that makes the changes in the crystal structure which is consistent with morphological studies. The $\mathrm{Yb}$ co-doped $\mathrm{ZnO}$ nanoparticles show the significant changes in the PL spectra as shown in figure $6 \mathrm{~b}$. Compared with the PL spectrum of pure $\mathrm{ZnO}$, UV emission of $\mathrm{Yb}$-doped $\mathrm{ZnO}$ nanoparticles exhibits smaller blue shift and the green emission band is sharply suppressed. For RE-doped $\mathrm{ZnO}$ nanoparticles, more electrons are contributed by dopants which would take up the energy levels located at the bottom of the conduction band. When they were excited by the laser of $325 \mathrm{~nm}$, the excitons take up higherenergy levels at the bottom of the conduction band and radioactive recombination of these excitons leads to a blue shift. ${ }^{38}$ This blue shift of UV emission reveals the incorporation of $\mathrm{Yb}$ ions on $\mathrm{Zn}$ lattice sites which supports the X-ray studies. ${ }^{36}$ With increasing of $\mathrm{Yb}$ 

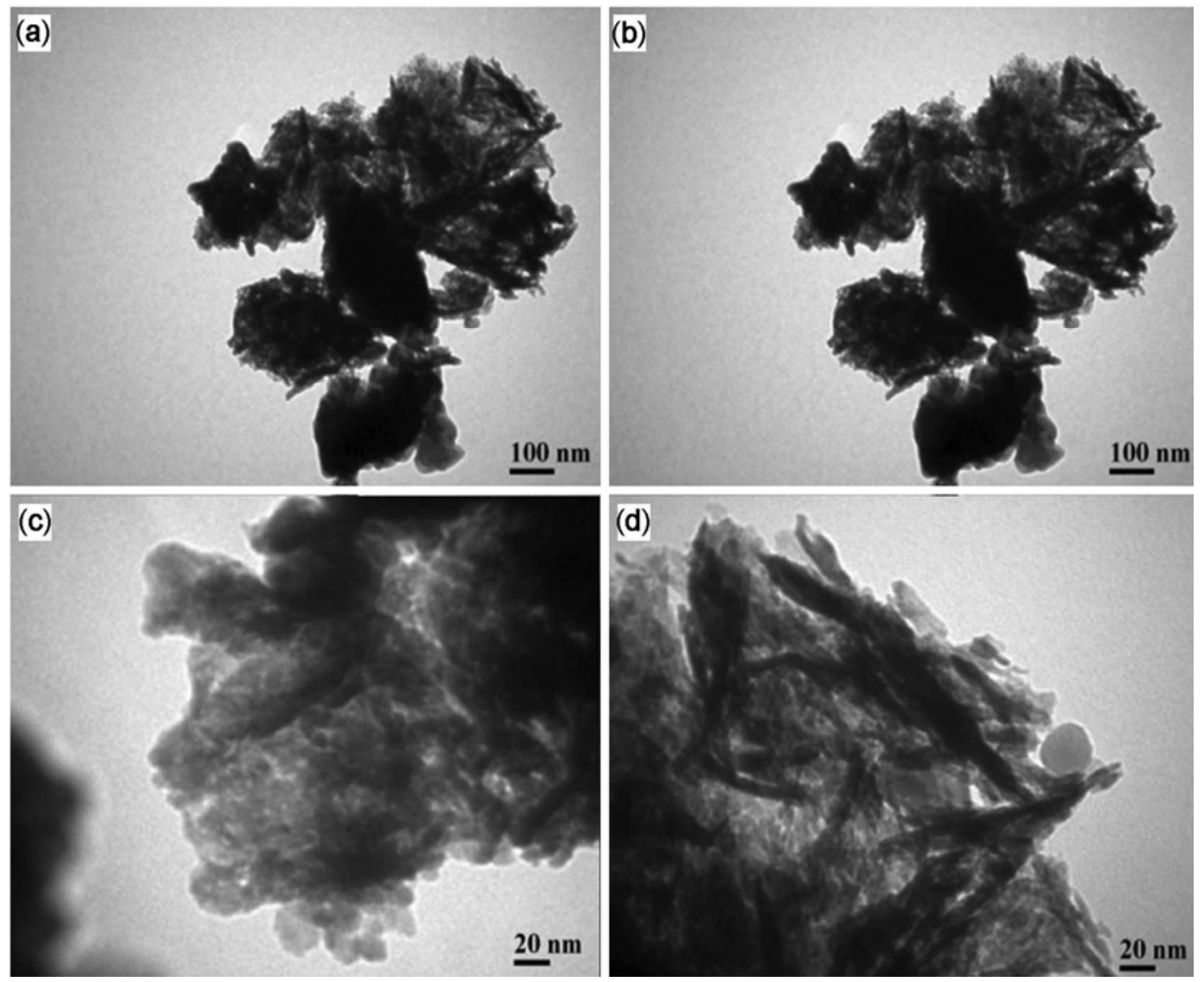

Figure 4. (a-d) TEM images of $\mathrm{ZnO}$ : Co doped with $1 \% \mathrm{Yb}$ nanoparticles.
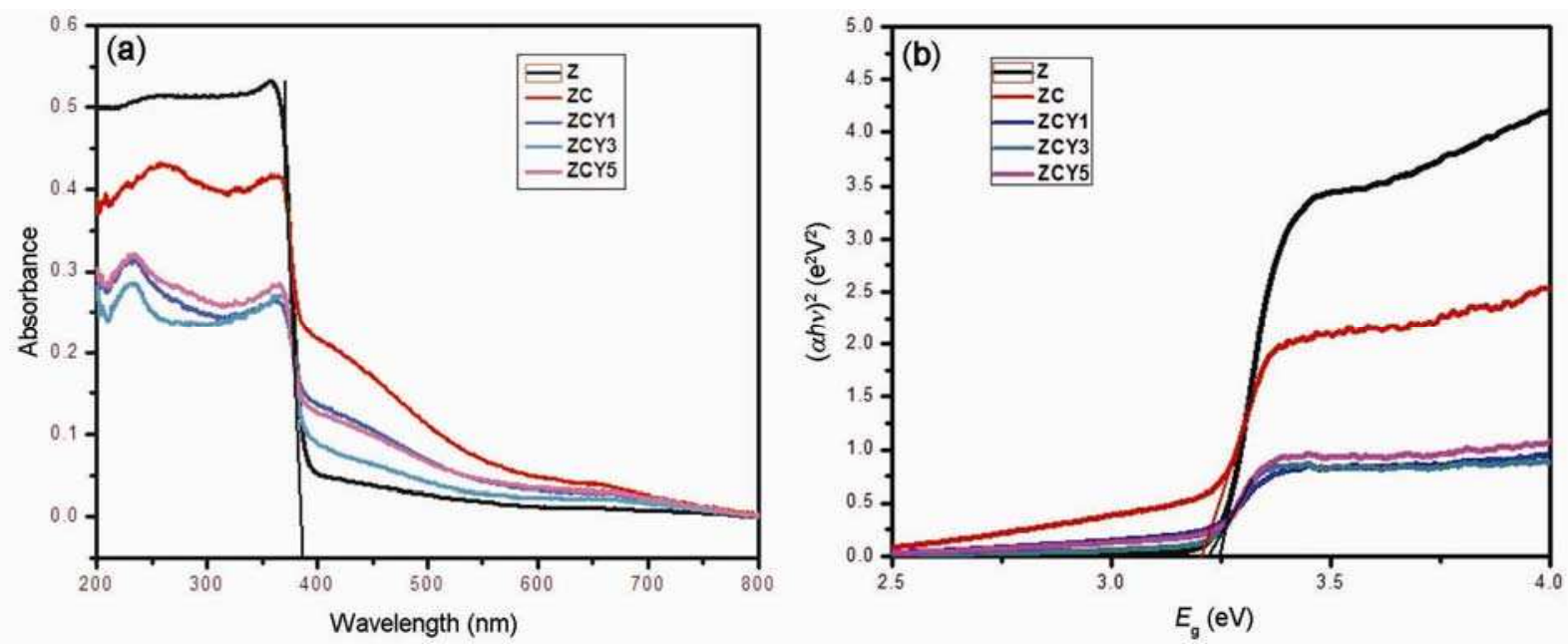

Figure 5. (a) UV-vis absorption spectra of pure and $\mathrm{Co}$ with $\mathrm{Yb}$ co-doped $\mathrm{ZnO}$ nanoparticles and (b) bandgap spectra of pure and $\mathrm{Co}$ with $\mathrm{Yb}$ co-doped $\mathrm{ZnO}$ nanoparticles.

concentration, the blue emission has been observed in the PL spectra with the increase in intensity. This arises from the doped $\mathrm{Yb}$ ions that introduced a new impurity level into energy bandgap of $\mathrm{ZnO}$, which leads to different transitions and gives blue emission. ${ }^{39}$ Based on previous literatures, the enhanced intensity of the blue emission confirms that the increased density of defects, which could be attributed to the defect introduced by the existence of $\mathrm{Yb}$ impurities in $\mathrm{ZnO}$ nanoparticles. ${ }^{36,39,40}$ Also the occurrence of blue emission at $440 \mathrm{~nm}$ is associated 

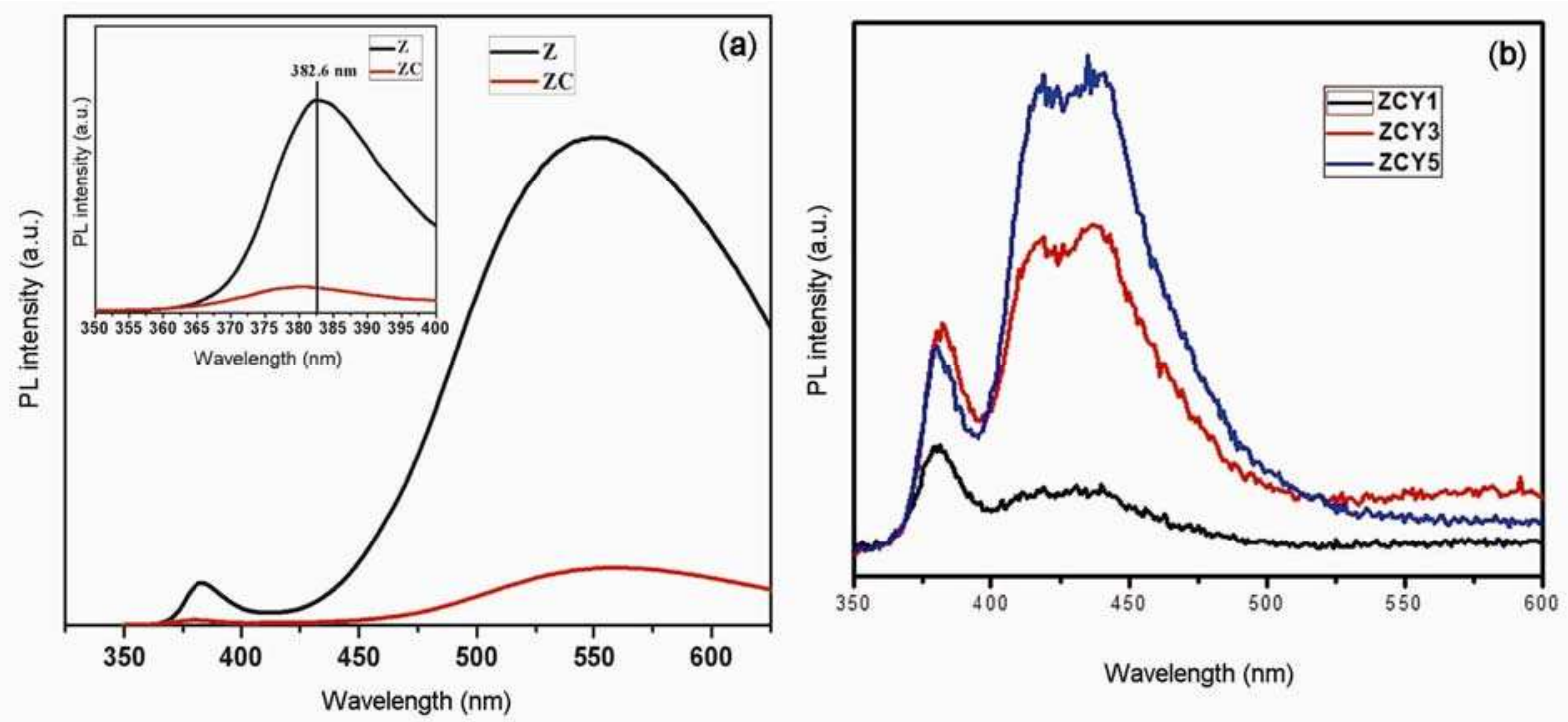

Figure 6. $\mathrm{PL}$ spectra of (a) pure and Co-doped $\mathrm{ZnO}$ nanoparticles and (b) Co with $\mathrm{Yb}$ co-doped $\mathrm{ZnO}$ nanoparticles.

with defect centres present below the conduction band of $\mathrm{ZnO}$ nanoparticles. This confirms the influences of $\mathrm{Yb}$ in luminescent behaviour of $\mathrm{ZnO}$ nanoparticles by introducing additional energy transitions within the $\mathrm{ZnO}$ lattices. The observed enhanced blue emission on PL spectra confirms that the $\mathrm{Yb}^{3+}$ ions are successfully substituted into $\mathrm{ZnO}$ lattice. Moreover, the fact that the intensity of $\mathrm{Yb}-\mathrm{PL}$ is comparable or higher than that of $\mathrm{ZnO}$ which indicates that the transfer from $\mathrm{ZnO}$ to $\mathrm{Yb}^{3+}$ ions can be quite efficient. ${ }^{40}$ Also the enhancement of UV-emission may be due to the following reasons: (i) $\mathrm{ZnO}$ lattice consists of a singly ionized oxygen vacancies which may be affected by the $\mathrm{Yb}^{3+}$ doping, (ii) creation of more electron-hole pairs with $\mathrm{Yb}^{3+}$ doping and (iii) energy transfer process from $\mathrm{Yb}^{3+}$ ions to $\mathrm{ZnO} .^{34,40}$ This result of $\mathrm{UV}$-vis absorption spectra is consistent with earlier reports.

\subsection{Magnetic studies}

DMSs based on the RE: $\mathrm{ZnO}$ exhibit larger magnetic moments due to their strong FM coupling between f-electron of RE ions and s-electrons in host semiconductor. ${ }^{25}$ Furthermore, the origin of ferromagnetism in REdoped semiconductors is not yet confirmed because of the controversial reports. It is well demonstrated that the presence of f-electrons in appropriate concentration can enhance the FM coupling in the RE diluted semiconductor oxides. ${ }^{28}$ However, the results do not convince the scientists. Therefore, it is important to realize the FM features of RE-doped semiconductors.

RT hysteresis curve for $\mathrm{Co}$ - and $\mathrm{Yb}$-doped $\mathrm{ZnO}$ nanoparticles is shown in figure $7 \mathrm{a}$ and $\mathrm{b}$. It can be seen that pure $\mathrm{ZnO}$ nanoparticles show only paramagnetism.
Doped $\mathrm{ZnO}$ with $\mathrm{Co}$ alone exhibits weak ferromagnetism without clear saturation as shown in figure $7 \mathrm{a}$ (red). The different concentrations of $\mathrm{Yb}$ added $\mathrm{ZnO}$ : $\mathrm{Co}$, nanoparticles show a significant variation in the $M-H$ curve. Noticeably, 1\% Yb-doped $\mathrm{ZnO}$ : Co nanoparticles exhibit RT ferromagnetism, which corresponds to the FM coupling between s-electrons of the Co and 4f-electron of $\mathrm{Yb}$ ions via $\mathrm{ZnO}^{28,41,42}$ It is mainly attributed to $1 \% \mathrm{Yb}$ which provides sufficient electron density to FM coupling and results in the well-established $M-H$ curve as shown in figure $7 \mathrm{~b}$. The origin of ferromagnetism may be due to the exchange interactions between localized electron spin moments, resulting from oxygen vacancies or defects in the $\mathrm{ZnO}$ samples. ${ }^{43}$ It is believed that the addition of $\mathrm{Yb}$ makes great influence on the hexagonal $\mathrm{ZnO}$ nanostructure by means of creating the $\mathrm{Zn}$ vacancy as well as Co clustering. This leads to the observed RTFM. Further increase in the $\mathrm{Yb}$ concentration to $5 \mathrm{~mol} \%$, the paramagnetic contribution is dominated, due to large number of localized $4 \mathrm{f}$ electrons in $\mathrm{Yb}$ ions. Unlike $3 \mathrm{~d}$ $\mathrm{TM}$ ions, in this case of mixed $3 \mathrm{~d}$ and $4 \mathrm{f}$ electrons coupling occur indirectly via $5 \mathrm{~d}$ or $6 \mathrm{~s}$ conduction electrons via host material. ${ }^{29}$ In addition, the presence of $\mathrm{Yb}^{3+}$ states may also directly influence the new exchange mechanism through intra-ion and inter-ion coupling, thus inducing ferromagnetism.

\subsection{XPS analysis}

XPS analysis was carried out for the sample $1 \%$-Ybdoped $\mathrm{Co}: \mathrm{ZnO}$ nanoparticle to further confirm the observed FM behaviour of both $3 \mathrm{~d}(\mathrm{Co})$ and $4 \mathrm{f}(\mathrm{Yb})$ ion-doped $\mathrm{ZnO}$ nanoparticles. Typical XPS spectra of the 

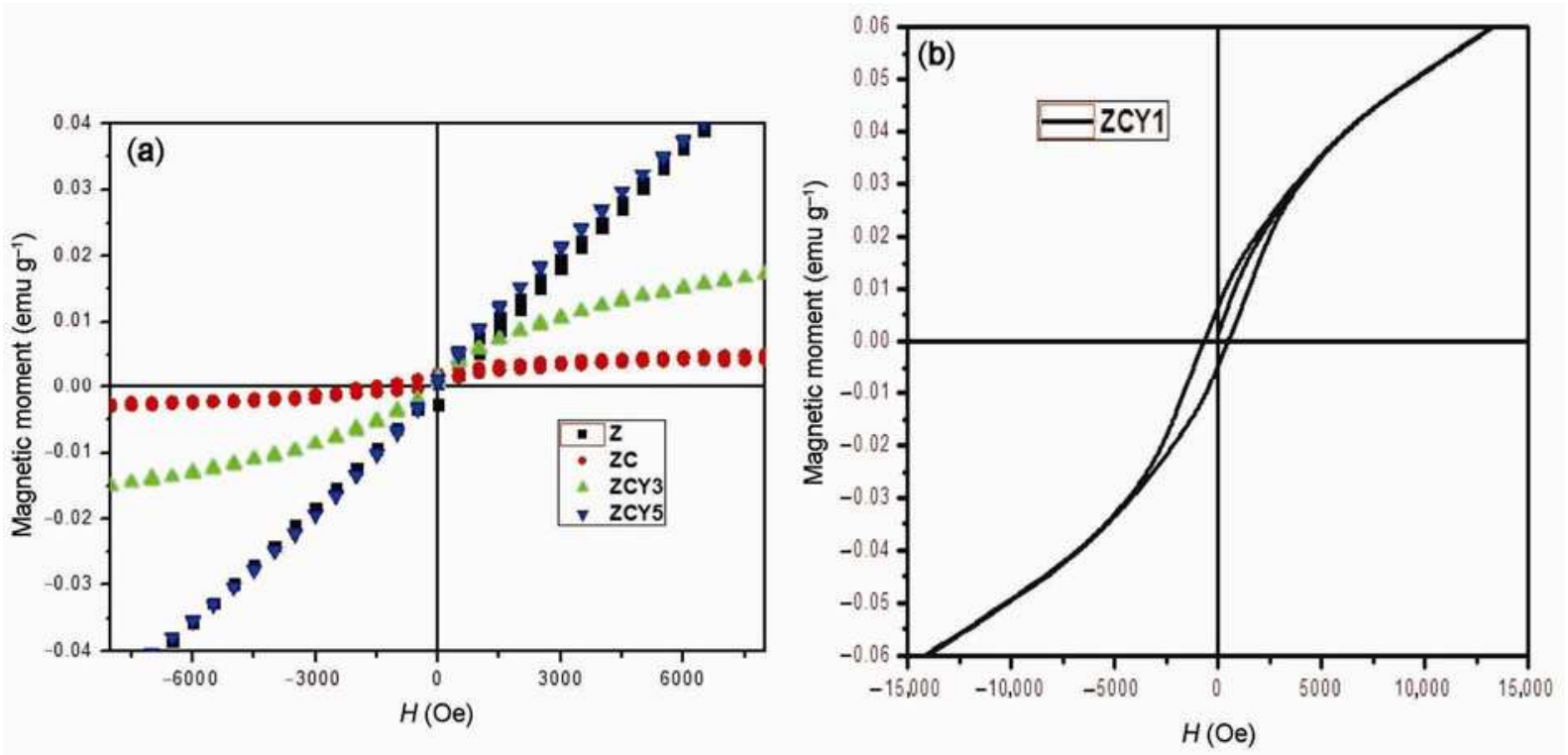

Figure 7. (a) Magnetization hysteresis $(M-H)$ curves of pure (inset), Co-doped (ZC), and Co with Yb co-doped (ZCY3 and ZCY5) $\mathrm{ZnO}$ nanoparticles and (b) magnetization hysteresis $(M-H)$ curves of $1 \% \mathrm{Yb}$ with Co-doped $\mathrm{ZnO}$ (ZCY1) nanoparticles.

(a)
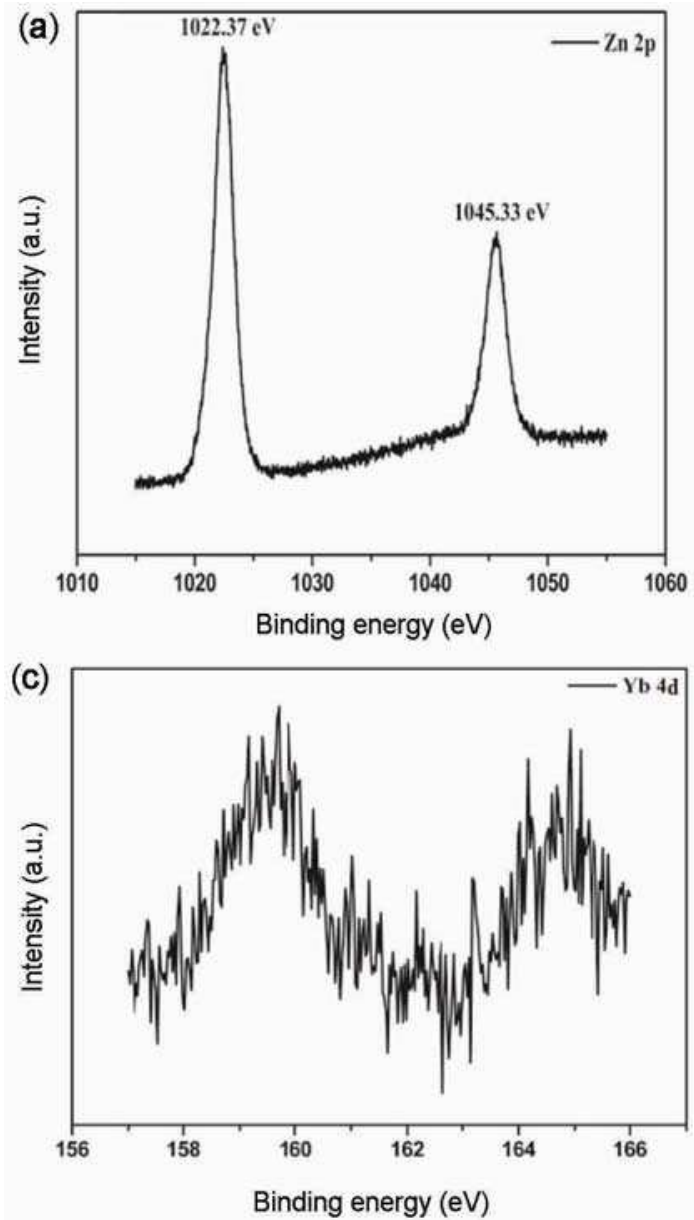

(b)
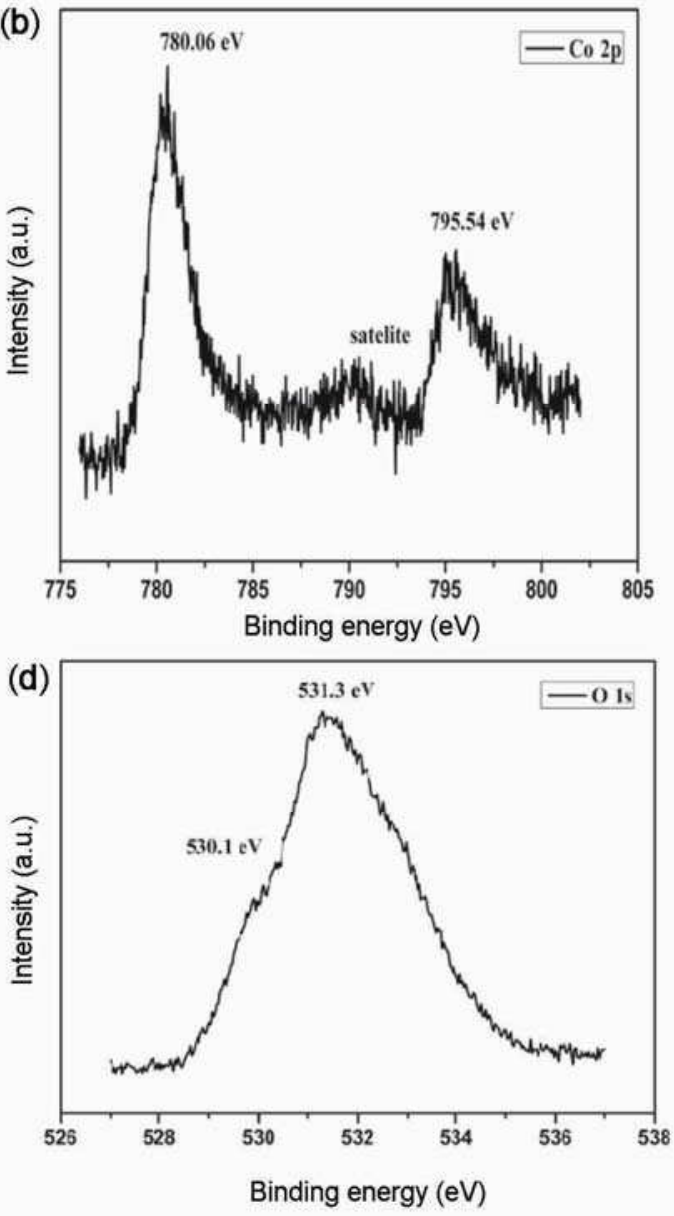

Figure 8. (a-d) XPS spectra of Co with $1 \% \mathrm{Yb}$ Co-doped $\mathrm{ZnO}$ nanoparticles. 
sample are illustrated in figure $8 \mathrm{a}-\mathrm{d}$. The XPS spectrum of Co $2 \mathrm{p}$ as shown in figure $8 \mathrm{~b}$ indicates the wellresolved $\mathrm{Co}^{2+}$ energy peaks at 780.06 and $795.54 \mathrm{eV}$ with the satellite peak at $\sim 790 \mathrm{eV}$. The energy difference between Co $2 p_{3 / 2}$ and Co $2 p_{1 / 2}$ is $15 \mathrm{eV}$, which matches with that of standard $\mathrm{CoO}$ and confirms the presence of $\mathrm{Co}^{2+}$ in $\mathrm{ZnO}$ lattices. ${ }^{44}$ The $\mathrm{Yb}-4 \mathrm{~d}$ peak in figure $8 \mathrm{c}$ reveals that two peaks with binding energies of 159 and $165 \mathrm{eV}$ are identified as $\mathrm{Yb} 4 \mathrm{~d}_{3 / 2}$ and $\mathrm{Yb} 4 \mathrm{~d}_{5 / 2}$, respectively. These findings suggest the presence of $\mathrm{Zn}$ and $\mathrm{Yb}$ in the doped $\mathrm{ZnO}$ nanoparticles in the form of $\mathrm{Zn} 2 \mathrm{p}$ and $\mathrm{Yb} 3 \mathrm{p}$ oxidation state. ${ }^{34,45}$ Hence, it can be confirmed that the imbalanced valence state of $\mathrm{Yb}$ has strongly interacted with the $\mathrm{Co}^{2+}$, thereby inducing RTFM. From the XPS spectra of $\mathrm{Zn} 2 \mathrm{p}$ and $\mathrm{O} 1 \mathrm{~s}$ as shown in figure $8 \mathrm{a}$ and $\mathrm{d}$, it is further understandable that $\mathrm{ZnO}$ can be highly desirable host semiconductor to make a facile dilute magnetic semiconductors. The strong XPS peaks at 1022.37 and $1045.33 \mathrm{eV}$ due to $\mathrm{Zn} 2 \mathrm{p}$ electron evidence the dominant $\mathrm{ZnO}$ phase that has been formed even after the $5 \%$ of $\mathrm{Yb}$ doping in addition to the Co. The two peaks situated at about 530.7 and $531.3 \mathrm{eV}$, respectively, corresponding to the binding energy of $\mathrm{Zn}-\mathrm{O}$ bonds in bulk $\mathrm{ZnO}$. The broad peak at $531.3 \mathrm{eV}$ may be related to the $\mathrm{O}^{2-}$ ions in the oxygen-deficient regions within the $\mathrm{ZnO}$ matrix, which indicates a good co-ordination between metal and oxygen. ${ }^{40}$ There is no additional peak found in the XPS survey spectrum due to impurities, which further confirms the phase stability of the semiconductor. From this investigation it can be concluded that the simultaneous doping of $\mathrm{Co}$ and $\mathrm{Yb}$ into $\mathrm{ZnO}$ increases the electron density and hole density in the host matrix. Here $\mathrm{Yb}^{3+}$ leads to the exchange interaction with $\mathrm{Co}$ through $\mathrm{ZnO}$ and thus facilitates the induced ferromagnetism.

\section{Conclusion}

In summary, the synthesis of pure $\mathrm{ZnO}$ nanoparticle with $\mathrm{Co}$ and $\mathrm{Yb}$ co-doping by the simple chemical precipitation method for dilute magnetic semiconductor applications is reported. The structure and optical features of the prepared samples are confirmed with XRD and photoluminescent analysis. As expected, $1 \% \mathrm{Yb}$ co-doped $\mathrm{ZnO}$ : Co nanoparticle exhibits ferromagnetism at RT. The observed ferromagnetism arises due to the combined exchange interaction between $3 \mathrm{~d}$ electron in $\mathrm{Co}^{2+}$ and delocalized $4 \mathrm{f}$ electron in $\mathrm{Yb}$ with the host. In particular, the occupation of $\mathrm{Yb}^{3+}$ state varies the hole and electron density with the $\mathrm{ZnO}$ system. It also favours the interand intra-band exchange interaction via $\mathrm{ZnO}$. Hence it induces the interesting low-field ferromagnetism in $\mathrm{Yb}$ co-doped $\mathrm{ZnO}$ nanoparticles. We conclude that $\mathrm{Yb}$ introduces the charge imbalance in $\mathrm{ZnO}$ with sufficient electron density at $1 \% \mathrm{Yb}$ co-doping, resulting in an exhibition of clear ferromagnetism at RT.

\section{References}

1. Zhang C-W, Wang P-J and Li F 2011 Solid State Sci. 131608

2. Tang G, Shi X, Huo C and Wang Z 2012 J. Ceram. 39 01329-6

3. Zhang Y G, Zhang G B and Wang Y X 2011 J. Appl. Phys. 109063510

4. Ip K, Frazier R M, Heo Y W, Norton D P, Abernathy C R and Pearton S J 2003 J. Vac. Sci. Technol. B 211476

5. Wang Y, Song Y, Yin S, Yu G, Miao J and Yuan S L 2006 Mater. Sci. Eng. B 1319

6. Zhu T, Zhan W S, Wang W G and Xiao J Q 2006 Appl. Phys. Lett. 89022508

7. Park J H, Kim M G, Jang H M, Ryu S and Kim Y M 2004 Appl. Phys. Lett. 84

8. Li B-B, Shen H-L, Zhang R, Xiu X-Q and Xie Z C 2007 Phys. Lett. 243473

9. Yang J H, Cheng Y, Liu Y, Ding X, Wang Y X, Zhang Y J and Liu H L 2009 Solid State Commun. 1491164

10. Snure M, Kumar D and Tiwari A 2009 Appl. Phys. Lett. 94 012510

11. Mishra A K and Das D 2010 Mater. Sci. Eng. B 1715

12. Ahn G Y, Park S-I, Kim S J and Kim C S 2006 J. Magn. Magn. Mater. 304 c498

13. Wang L M, Liao J-W, Peng Z-A and Lai J-H 2009 J. Electrochem. Soc. $156 \mathrm{H} 138$

14. Ferhat M, Zaoui A and Ahuja R 2009 Appl. Phys. Lett. 94 142502

15. Xing G, Wang D, Yi J, Yang L, Gao M, He M, Yang J, Ding J, Sum T C and Wu T 2010 Appl. Phys. Lett. 96112511

16. Hsu H S and Huang J C A 2006 Appl. Phys. Lett. 88 242507

17. Khalid M, Ziese M, Setzer A, Esquinazi P, Lorenz M, Hochmuth H, Grundmann M, Spemann D, Butz T, Brauer G, Anwand W, Fischer G, Adeagbo W A, Hergert W and Ernst A 2009 Phys. Rev. B 80035331

18. Banerjee S, Mandal M, Gayathri N and Sardar M 2007 Appl. Phys. Lett. 91182501

19. Xu Q, Schmidt H, Zhou S, Potzger K, Helm M, Hochmuth H, Lorenz M, Setzer A, Esquinazi P, Meinecke C and Grundmann M 2008 Appl. Phys. Lett. 92082508

20. Duan L B, Chu W G, Yu J, Wang Y C, Zhang L N, Liu G Y, Liang J K and Rao G D 2008 J. Magn. Magn. Mater. 3201573

21. Rao C N R and Deepak F L 2005 J. Mater. Chem. 15573

22. Hite J K, Frazier R M, Davies R P, Thaler G T, Abernathy C R, Pearton S J, Zavada J M, Brown E and Hömmerich U 2007 J. Electron. Mater. 36391

23. Zhou Y K, Choi S W, Emura S, Hasegawa S and Asahi H 2008 Appl. Phys. Lett. 92062505

24. Assadi M H N, Zhang Y B, Photongkam P and Li S 2011 J. Appl. Phys. 109013909

25. Subramanian M, Thakur P, Tanemura M, Hihara T, Ganesan V, Soga T, Chae K H, Jayavel R and Jimbo T 2010 J. Appl. Phys. 108053904

26. Ma X 2012 Thin Solid Films 5205752

27. Bantounas I, Goumri-Said S, Kanoun M B and Manchon A 2011 J. Appl. Phys. 109083929

28. Shi H, Zhang P, Li S-S and Xia J-B 2009 J. Appl. Phys. 106023910

29. Iqbal J et al 2009 J. Appl. Phys. 106083515 
30. Diaz-Torres L A, De la Rosa E, Salas P and Desirena H 2005 Opt. Mater. 271305

31. Jiang L, Xiao S, Yang X, Ding J and Dong K 2012 Appl. Phys. B 107477

32. Pal B and Giri P K 2010 J. Appl. Phys. 108084322

33. Roy B, Chakrabarthy S, Mondal O, Pal M and Dutta A 2012 Mater. Charact. 701

34. Kabongo $\mathrm{G} \mathrm{L}$, Mhlongo $\mathrm{G} \mathrm{H}$, Mothudi B M, Hillie $\mathrm{K} \mathrm{T}$, Swart H C and Dhlamini M S 2014 Mater. Lett. 11971

35. Lang J, Han Q, Yang J, Li C, Li X, Yang L, Zhang Y, Gao M, Wang D and Cao J 2010 J. Appl. Phys. 107074302

36. Opera O, Vasile O R, Voicu G, Craciun L and Andronescu E 2012 Digest J. Nanomater. Biostruct. 71757

37. Liu Z W, Ong C K, Yu T and Shen Z X 2006 Appl. Phys. Lett. 88053110
38. Yan J, Gao M, Yang L, Zhang Y, Lang J, Wang D, Wanga Y, Liu H and Fan H 2008 Appl. Surf. Sci. 2552646

39. Paul S, Choudhury B and Choudhury A 2014 J. Alloys Compd. 601201

40. Teng X M, Fan H T, Pan S S, Ye C and Li G H 2006 J. Appl. Phys. 100053507

41. Yoon H, Wu J H, Min J H, Lee J S, Ju J-S and Kim Y K 2012 J. Appl. Phys. $11107 \mathrm{~B} 523$

42. Assadi M H N, Zhang Y, Zheng R-K, Ringer S P and Li S 2011 Nanoscale Res. Lett. 6357

43. Wang C C, Liu M, Man B Y, Chen C S and Jiang S Z 2012 AIP Adv. 2012182

44. Chen X G, Yang Y B, Wua R, Liu R, Kong X D, Han L, Yang Y C and Yang J B 2011 Physica B 4061341

45. Ohno Y 2008 J. Electron. Spectrosc. Relat. Phenom. 1651 